\title{
Effect of Tin on the Structure, Mechanical and Tribological Properties of Sintered Al-12Si Alloy
}

\author{
Nikolay M. Rusin*a, \\ Alexandr L. Skorentsev ${ }^{\mathrm{a}, \mathrm{b}}$ and Alexey V. Gurskikh ${ }^{\mathrm{c}}$ \\ ${ }^{a}$ Institute of Strength Physics and Materials Science of SB RAS \\ 2/4 Akademicheskii, Tomsk, 634055, Russia \\ ${ }^{b}$ Tomsk Polytechnic University \\ 30 Lenina, Tomsk, 634050, Russia \\ c JSC «POLEMA» \\ 3 Przhevalskogo Str., Tula, 300016, Russia
}

Received 26.01.2018, received in revised form 17.03.2018, accepted 29.04.2018

The structure, mechanical and tribological properties of composites produced by sintering of mixtures of Al-12Si alloy and tin powders were investigated. The sintering of the briquettes was carried out in a vacuum at $570{ }^{\circ} \mathrm{C}$ after their preliminary exposure at $550{ }^{\circ} \mathrm{C}$ for one hour. It was established that liquid-phase sintering on the specified regime makes it possible to obtain the (Al-12Si)-xSn composites with continuous aluminum matrix in a wide range of tin content. The final porosity of the samples remained practically unchanged with increasing sintering time, but the ductility of the composites was improved. In order to eliminate the residual porosity the (Al-12Si)-xSn composites were subjected to hot densification at temperatures above and below the melting point of tin. It was found that the temperature of hot densification has little effect on the strength of the composites. The value of the strength is determined by the rule of the ideal mixture. Whereas the wear resistance under dry friction of the densificated composites improves with increasing tin content. This effect is especially noticeable at high loads.

Keywords: sintered Al-Si-Sn composites, structure, mechanical and tribological properties, dry friction.

Citation: Rusin N.M., Skorentsev A.L., Gurskikh A.V. Effect of tin on the structure, mechanical and tribological properties of sintered Al-12Si alloy, J. Sib. Fed. Univ. Eng. technol., 2018, 11(4), 433-442. DOI: 10.17516/1999-494X-0066.

(C) Siberian Federal University. All rights reserved

* Corresponding author E-mail address: rusinnm@mail.ru, skoralexan@mail.ru 


\title{
Влияние олова на структуру, механические \\ и трибологические свойства спечённого сплава Al-12Si
}

\author{
Н.М. Русин ${ }^{\mathrm{a}}$, А.Л. Скоренцев ${ }^{\mathrm{a}, \boldsymbol{\sigma}}$, А.В. Гурских ${ }^{\mathrm{B}}$ \\ ${ }^{a}$ Институт физики прочности и материаловедения СО РАН \\ Россия, 634055, Томск, пр. Академический, 2/4 \\ ${ }^{6}$ Томский политехнический университет \\ Россия, 634050, Томск, пр. Ленина, 30 \\ ${ }^{8} \mathrm{AO}$ «Полема» \\ Россия, 300016, Тула, ул. Пржевальского, 3
}

Исследованы структура, механические и трибологические свойства композитов, полученных спеканием смесей порошков сплава Al-12Si и олова. Спекание брикетов осуществляли в вакууме при $570{ }^{\circ} \mathrm{C}$ после обязательной их выдержки в течение 1 ч при температуре $550{ }^{\circ} \mathrm{C}$. Установлено, что жидкофазное спекание по указанному режиму позволяет получать композиты (Al-12Si)$x \mathrm{Sn}$ со связанной алюминиевой матрицей в широком диапазоне содержания олова. Конечная пористость образиов с увеличением длительности их спекания практически не менялась, но пластичность композитов улучшалась. Для устранения остаточной пористости композиты (Al-12Si)-xSn были допрессованы при температуре выше и ниже плавления олова. Обнаружено, что температура допрессовки мало влияет на прочность композитов, и её величина определяется правилом идеальной смеси. Тогда как износостойкость доуплотнённых композитов при сухом трении, наоборот, улучшается с ростом содержания в них олова, особенно это заметно при больших нагрузках.

Ключевые слова: спечённые композиты Al-Si-Sn, структура, механические и трибологические свойства, трение без смазки.

\section{Введение}

Широта применения алюминиевых сплавов в качестве материалов для трения ограничивается их склонностью к схватыванию при контакте с твёрдым контртелом. Однако если при трении удаётся обеспечить условия, исключающие схватывание, использовать в узлах трения изделия из лёгких алюминиевых сплавов становится выгодно. Например, в двигателестроении активно используются изделия из силуминов, отличающиеся помимо износостойкости хорошей жидкотекучестью и низким коэффициентом термического расширения [1].

Однако обеспечить стабильную подачу смазки на поверхность трения не всегда удаётся, например, в моменты пуска или остановки машин, и тогда между сопряжёнными телами узла трения возможен кратковременный непосредственный контакт. В этом случае наилучшей износостойкостью обладают силумины с большим содержанием кремния, частицы которого выступают над поверхностью и не дают соприкасаться алюминиевой матрице с контртелом. Правда, из-за высокой концентрации кремния и неизбежного присутствия крупных и хрупких кристаллов первичного кремния ухудшаются другие характеристики силуминов, такие как пластичность и обрабатываемость давлением.

Большое количество кремния приводит также к снижению теплопроводности силуминов. Для используемых в узлах трения изделий этот факт неблагоприятен, поскольку медленный 
отвод тепла с поверхности трения приводит к разогреву прилегающего слоя, снижению его прочности и твёрдости. Выступающие над поверхностью частицы кремния вдавливаются в размягчённый поверхностный слой, и между Al матрицей и контртелом становится возможным непосредственный контакт и схватывание.

Традиционным путём борьбы с изнашиванием алюминия схватыванием является его легирование веществами с низким сопротивлением сдвигу. При деформации верхнего слоя трущейся детали включения из мягких веществ выдавливаются на поверхность трения и размазываются по ней тонкой плёнкой, препятствующей непосредственному контакту контртел. В настоящее время с этой целью чаще всего используют добавки мягкого олова (ГОСТ 14113-78), и чем выше его концентрация, тем при большем давлении наступает схватывание между алюминиевым подшипником и валом [2, 3].

Однако, как и в случае с кремнием, рост концентрации олова отрицательно сказывается на пластичности сплавов Al-Sn вследствие ухудшения связанности зёрен алюминиевой матрицы. Протяжённость границ между ними уменьшается ещё на стадии кристаллизации расплава Al-Sn, когда растворимость олова в твёрдом алюминии резко снижается и ставшее излишним олово окружает выпавшие Al частички. Чем больше олова в расплаве, тем толще и протяжённее его прослойки между зёрнами матрицы. Такая фрагментация несущей матрицы ослабляет её, и при нагружении композитов пластическое течение локализуется в мягкой фазе, резервы пластичности тонких прослоек которой при этом быстро исчерпываются.

Согласно альтернативному мнению [4], причиной разрушения межфазных границ Al-Sn выступает высокая насыщенность их водородом из атмосферы. Поэтому в сплавах, где олово образует непрерывную сетку, водород имеет возможность диффундировать на большую глубину и вызывать охрупчивание всего материала. Это плохо сказывается на обрабатываемости сплавов с большим содержанием олова давлением.

Таким образом, и кремний, и олово ухудшают пластичность алюминия. В сплавах $\mathrm{Al}-\mathrm{Si}$ особенно заметно это проявляется при концентрации кремния выше эвтектической, а пластичность сплавов Al-Sn резко снижается при концентрации олова выше 20 \% вес. В то же время указанные добавки эффективно снижают интенсивность изнашивания Al схватыванием. Можно ожидать, что одновременное присутствие обоих легирующих компонентов окажет мультипликативный эффект на износостойкость алюминия, без значительного ухудшения его пластичности. Например, в работе [5] был испытан на трение сплав Al-17Si-10Sn, полученный напылением на медную охлаждаемую подложку. Износостойкость такого сплава оказалась заметно выше износостойкости полученного и испытанного в тех же условиях силумина без олова.

То есть даже небольшое ( 5 \% об.) количество олова благоприятно сказывается на износостойкости силуминов. Можно ожидать, что их трибологические свойства дополнительно улучшатся при более высокой концентрации олова, если при этом решить следующие задачи: сохранить связанность зёрен Al матрицы и не допустить значительного увеличения числа контактов между частицами кремния и олова, поскольку жидкое олово плохо смачивает кремний и межфазные границы «Si-Sn» получаются непрочными.

При литьевом способе получения трёхкомпонентного материала Al-Si-Sn c большой концентрацией олова избежать фрагментации алюминиевой матрицы оловянными прослойками и множественных контактов «Sn-Si» практически невозможно. Однако было показано [6], что

$$
-435-
$$


сохранить связанность матрицы в бинарном сплаве Al-Sn при весовой концентрации олова до 50 \% можно с помощью методов порошковой металлургии. Целью настоящей работы является проверка применимости данного подхода для получения композиционного материала (КМ) состава (Al-Si)-xSn, для формирования матрицы которого использован распылённый порошок силумина, а также исследование механических и трибологических свойств полученных таким образом композитов.

\section{Материалы и методика эксперимента}

В качестве основы нового КМ был выбран порошок эвтектического состава, полученный распылением расплава Al-12Si в атмосфере азота. К нему в различных пропорциях с шагом в 10 \% (вес.) подмешивали порошок олова марки ПО2. Полученные смеси прессовали в шайбы диаметром 20 мм, которые затем подвергали спеканию по выбранному режиму в вакуумной печи марки СНВЭ. Спечённые заготовки исследовались на содержание в них пор, и определялся характер сформировавшейся структуры. Затем шайбы доуплотнялись при 200 и $250{ }^{\circ} \mathrm{C}$, а их структура исследовалась повторно с тем, чтобы связать её изменения с возросшими механическими свойствами материала. Прочность материала определяли путём сжатия на машине Walter+BaiAGLFM-125 со скоростью осадки 0,5 мм/мин.

Исследования структуры КМ проводили с помощью сканирующего электронного микроскопа. Шлифы для исследований готовились по обычной методике: шлифованием на наждачной бумаге, затем полированием на сукне с нанесённой на него алмазной пастой и последующим химическим травлением поверхности в 4\%-ном растворе $\mathrm{HNO}_{3}$ в спирте.

Триботехнические испытания спечённых КМ проводили по схеме «палец-диск» на триботестере фирмы «Tribotechnic» (France). Давление на поверхность трения испытываемых образцов составляло 1-5 МПа, а скорость скольжения - 0,6 м/с. Диск был изготовлен из закалённой стали марки ст. 45 , имевшей твёрдость около $47 \mathrm{HRc}$. Перед испытаниями его поверхность подготавливалась по той же методике, что и шлифы на образцах, а затем промывалась в ацетоне. Торцевая поверхность испытываемых образцов также шлифовалась до зеркального блеска и перед испытаниями протиралась ацетоном.

\section{Результаты и их обсуждение}

На рис. 1 представлена структура образца из порошков сплава Al-12Si, спечённого вблизи температуры плавления эвтектики $\left(577{ }^{\circ} \mathrm{C}\right)$. Видно, что указанной температуры было недостаточно, чтобы инициировать активный диффузионный рост шеек между порошинками и слияние частиц, сопровождающееся сближением центров их масс. За исключением немногих контактов в виде шеек спекания, большинство границ между порошинками несовершенного типа и содержат поры (рис. 1б). Спекание порошков эвтектического состава при более высокой температуре невозможно ввиду полного расплавления образцов.

Несомненно, что спеканию порошков препятствует также оксидная плёнка на их поверхности, имеющая, судя по содержанию кислорода (рис. 1a), значительную толщину. Скорее всего, кислород проник также и по границам «Al-Si» и активно препятствовал диффузионному растворению кремния в алюминии, что позволило нагревать порошки сплава даже несколько выше температуры образования эвтектики.

$$
-436-
$$




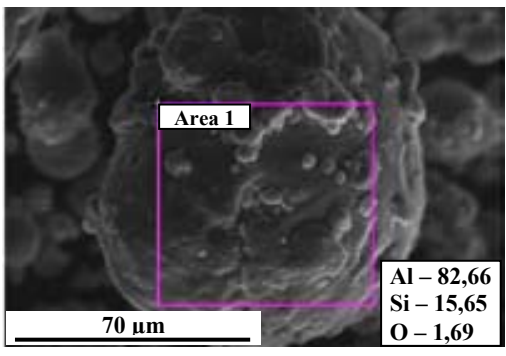

a

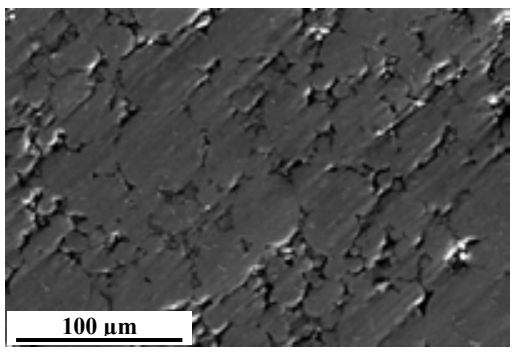

б

Рис. 1. Вид и весовой состав (\%, на врезке) порошков Al-12Si (a), а также структура прессовки после спекания при $588^{\circ} \mathrm{C}, 1$ ч (б)

Fig. 1. Image and composition (wt. \%, on the inset) of Al-12Si powders (a), and structure of the compact after sintering at $588^{\circ} \mathrm{C}$ for 1 hour (б)

Если в прессовку добавить легкоплавкого олова, то спекание порошков Al-12Si будет проходить в присутствии жидкой фазы. Известно, что основным условием для получения в этом случае высокоплотного материала является хорошая растворимость твёрдой фазы в жидкой [7]. Согласно диаграмме состояния Al-Sn, растворимость твёрдого алюминия в жидком олове при повышении температуры растёт, а значит, получить плотный материал из смеси жидкого олова с порошками Al-12Si, в принципе, возможно. Правда, для этого необходимо, чтобы оксидные плёнки при спекании не препятствовали непосредственному контакту олова с чистой алюминиевой поверхностью.

Ранее было установлено [8], что для выполнения последнего условия при спекании брикетов из смеси порошков $\mathrm{Al}$ и $\mathrm{Sn}$ требуется 30-минутная их выдержка при температуре выше $600{ }^{\circ} \mathrm{C}$. За это время расплав олова проникает под поверхностные оксидные плёнки на алюминиевых порошинках и растекается по прессовке. Дальнейшее уплотнение образцов происходит за счёт более плотной переукладки частиц твёрдой фазы под действием стягивающих капиллярных сил. Увеличению подвижности частиц способствует выведение их из зацепления за счёт проникновения жидкости на контакты и растворения в ней наиболее мелких порошинок или поверхностных неровностей крупных частиц.

Однако если двугранный угол смачивания твёрдой фазы жидкостью больше нуля, то подвижность порошинок быстро снижается, поскольку сближающиеся частицы начинают сталкиваться между собой и срастаться в местах контактов. Уплотнение каркаса из сросшихся частиц происходит путём коагуляции соседних зёрен, сопровождающейся сближением их центра масс. Если же угол смачивания равен нулю, то жидкая прослойка не позволяет порошинкам срастаться, но процесс растворения и перекристаллизации растворившихся атомов продолжается. В любом случае, уплотнение спекаемого тела контролируется диффузионными процессами, ведущими, в конечном итоге, к снижению числа частиц твёрдой фазы и росту их размеров, т. е., к огрублению структуры КМ. В случае системы Al-Sn граничной, определяющей преобладающее действие того или иного механизма является температура $620^{\circ} \mathrm{C}$, при которой угол смачивания оловом алюминия становится равным нулю [9]. В зависимости от температуры спекания рост частиц твёрдой фазы (Al) происходит преимущественно либо путём их сращивания, либо за счёт перекристаллизации растворённых атомов Al через жидкую фазу [10].

$$
-437 \text { - }
$$


Ввиду толстой оксидной плёнки (рис. 1a) на порошках сплава Al-12Si спеканию их в смеси с оловом также должна предшествовать предварительная выдержка, обеспечивающая установление контактов жидкого олова непосредственно с чистой поверхностью Al-частиц. Путём подбора температуры спекания и времени выдержки образцов состава (Al-12Si)-xSn было установлено, что для разрушения оксидной плёнки на порошках и инициации их активного взаимодействия с расплавом необходима предварительная выдержка прессовок в присутствии жидкого олова при температуре $550^{\circ} \mathrm{C}$ не менее 1 ч.

За это время происходит разрушение оксидной плёнки на олове (возможно, вследствие частичного растворения её в расплаве), проникновение жидкости под оксидные плёнки и её растекание по поверхности Al-частиц. Однако угол смачивания алюминия оловом остаётся достаточно большим [9], поэтому растекание его неполное и обширные участки поверхности алюминиевых порошинок остаются несмоченными даже после спекания при температуре, максимально близкой к температуре образования эвтектики.

Влияние времени спекания на результирующую структуру композита с 40 \% олова показано на рис. 2. Видно, что при нагреве до $570{ }^{\circ} \mathrm{C}$ жидкость проникает на большинство границ между порошинками сплава Al-12Si. Первые 30 мин спекания частицы преимущественно растворяются с поверхности, становятся более округлыми и растут за счёт осаждения на них атомов алюминия из пересыщенной жидкости. По мере растворения наименьших твёрдых частиц интенсивность растворения оставшихся падает из-за насыщения жидкости атомами алюминия и покрытия оставшихся частиц слоем материала, находящегося в равновесии с жидкостью. Тем не менее огрубление структуры композитов продолжается, поскольку, столкнувшись, частицы твёрдой фазы могут срастаться, о чём свидетельствует больший размер и менее округлая форма частиц твёрдой фазы на рис. 26 .

Подвижность агломератов из касающихся и сросшихся частиц низкая. Поэтому интенсивность уплотнения образцов за счёт перегруппировки твёрдых частиц резко снижается, и каркас из них остаётся пористым даже после 2-часовой выдержки при $570{ }^{\circ} \mathrm{C}$. Более того, к существующим порам в процессе спекания добавляются ещё и газовые поры, поскольку

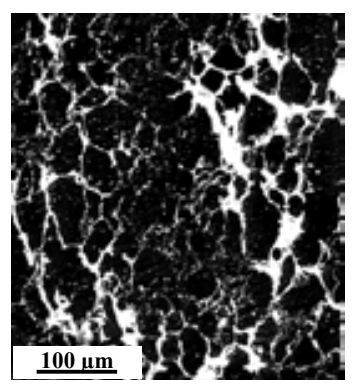

a

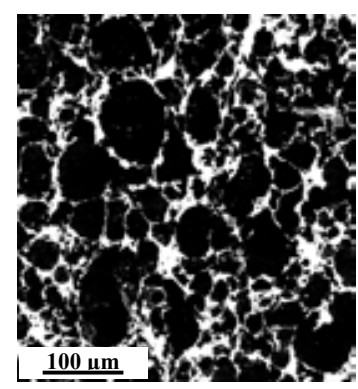

б

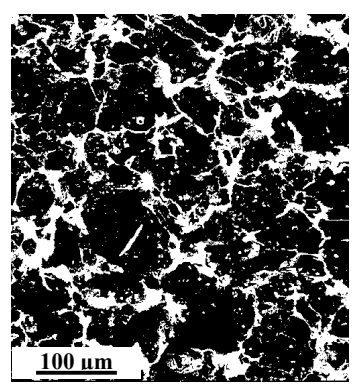

B

Рис. 2. Структура композита (Al-12Si)-40Sn, спечённого при $570{ }^{\circ} \mathrm{C}$. Время выдержки, мин: a - 10; б - 30; B -120

Fig. 2. Structure of the (Al-12Si) $-40 \mathrm{Sn}$ composite sintered at $570{ }^{\circ} \mathrm{C}$. Sintering duration, min: a $-10 ; 6-30$; B -120 
Таблица 1. Влияние концентрации олова и температуры допрессовки на прочность спечённых образцов (Al-12Si)-xSn. Температура спекания $570{ }^{\circ} \mathrm{C}$, время выдержки 10 мин

Table 1. Effect of tin content and temperature of densification on the strength of the sintered (Al-12Si)-xSn samples. The sintering temperature was $570{ }^{\circ} \mathrm{C}$, and holding time $10 \mathrm{~min}$

\begin{tabular}{|c|c|c|c|c|c|c|c|c|}
\hline \multirow{3}{*}{ Температура допрессовки, ${ }^{\circ} \mathrm{C}$} & \multicolumn{8}{|c|}{ Концентрация олова, вес. \% } \\
\hline & \multicolumn{2}{|c|}{10} & \multicolumn{2}{|c|}{20} & \multicolumn{2}{|c|}{30} & \multicolumn{2}{|c|}{40} \\
\hline & $\begin{array}{c}\sigma_{0.2}, \\
\text { МПа }\end{array}$ & $\begin{array}{c}\sigma_{\mathrm{B}}, \\
\text { МПа }\end{array}$ & $\begin{array}{c}\sigma_{0.2}, \\
\text { МПа }\end{array}$ & $\begin{array}{c}\sigma_{\mathrm{B}}, \\
\mathrm{M \Pi а}\end{array}$ & $\begin{array}{c}\sigma_{0.2}, \\
\text { МПа }\end{array}$ & $\begin{array}{c}\sigma_{\mathrm{B}}, \\
\mathrm{M \Pi а}\end{array}$ & $\begin{array}{c}\sigma_{0.2}, \\
\text { МПа }\end{array}$ & $\begin{array}{c}\sigma_{\mathrm{B}}, \\
\mathrm{M \Pi а}\end{array}$ \\
\hline спеченный & - & - & - & - & 27 & 31 & 44 & 60 \\
\hline 200 & 124 & 160 & 116 & 149 & 111 & 133 & 98 & 123 \\
\hline 250 & 121 & 163 & 109 & 153 & 103 & 135 & 91 & 119 \\
\hline
\end{tabular}

в процессе перекристаллизации твёрдофазных частиц высвобождается водород, которого в силуминах, как известно [1], может содержаться большое количество.

Таким образом, прочность спечённого композита из-за большого количества в материале пор и несовершенства межфазных границ остаётся невысокой. Образцы преждевременно разрушаются даже при нагружении их сжатием и оказываются тем слабее, чем меньше в них олова. Для повышения прочности и пластичности спечённых образцов они были подвергнуты горячей допрессовке, результаты которой приведены в табл. 1.

Как следует из табличных данных, спечённые сплавы после горячей их допрессовки (особенно с 10 и 20 \% олова) по прочности приближаются к содержащему около 12 \% кремния литейному сплаву АЛ 2 ( $\sigma_{\text {в }}=150$ МПа) [1]. Причём предел упругости $\left(\sigma_{0.2}\right)$ у прессованных при температуре $200{ }^{\circ} \mathrm{C}$ композитов выше, чем у образцов, прессованных при $250{ }^{\circ} \mathrm{C}$. Видимо, это обусловлено меньшим размером зёрен матрицы в композитах из-за меньшей температуры их нагрева при обжатии. Предел же прочности, наоборот, у обработанных при $250{ }^{\circ} \mathrm{C}$ композитов выше, чем у прессованных при $200{ }^{\circ} \mathrm{C}$ из-за того, что границы фаз в этом случае получаются более совершенными и материал способен выдержать большие деформации, а матрица сильнее упрочниться.

Для более наглядной демонстрации влияния олова на прочность спечённых композитов (Al-12Si)-xSn на рис. 3 приведены графики зависимости «б - $\mathrm{C}_{\mathrm{Sn}}$ ». Видно, что значения прочности $\sigma_{0.2}$ и $\sigma_{\mathrm{B}}$ с высокой точностью ложатся на прямые, причём прямая максимальной прочности $\sigma_{\mathrm{B}}$ наклонена под большим углом. Это говорит о том, что с увеличением концентрации олова прослойки его становятся всё более разветвлёнными, что приводит к снижению темпов упрочнения KM (Al-12Si)-xSn (а фактически - матрицы) из-за увеличения числа межфазных границ, вблизи которых возможно аккомодационное течение, приводящее к понижению напряжения в головах дислокационных скоплений. Преимущественная локализация пластического течения в прослойках мягкой фазы при большом её содержании также может быть дополнительной причиной снижения темпов упрочнения композитов с оловом, как, например, в сплаве (Al12Si)-40Sn (табл. 1).

Прямолинейная зависимость «б $-\mathrm{C}_{\mathrm{Sn}}$ » указывает, что прочность композитов подчиняется правилу идеальной смеси не только при упругом их нагружении, но и при пластическом течении. Последнее означает, что деформация распределяется в исследуемых образцах равномерно

$$
-439-
$$


и прочность КМ (Al-12Si)-xSn определяется по формуле $\sigma_{\mathrm{KM}}=\sigma(\mathrm{M}) \mathrm{C}_{\mathrm{M}}+\sigma(\mathrm{Sn}) \mathrm{C}_{\mathrm{Sn}}$, где $\mathrm{C}_{\mathrm{M}}-$ концентрация матричного элемента, а $\sigma(\mathrm{M})=\sigma_{0}+\theta \varepsilon^{\mathrm{n}}$ есть прочность деформируемой матрицы с коэффициентом деформационного упрочнения ө.

Различное количество (х) мягкого олова влияет не только на прочность КМ (Al-12Si)-xSn, но и на их износостойкость при сухом трении. Из приведённых в табл. 2 данных следует, что величина коэффициента трения, рассчитанного по формуле Амонтона-Кулона, практически не зависит от содержания в композитах олова. Может также сложиться впечатление, что с ростом давления сила трения образцов по стали убывает. Однако нужно учесть, что $\mathrm{F}_{\mathrm{fr}}=\mu \cdot \mathrm{N}=\mu \cdot(\mathrm{P} \cdot \mathrm{S})$, где $\mathrm{N}$ - нормальная к площадке трения площадью $\mathrm{S}$ нагрузка. Тогда можно перейти к такой характеристике, как удельная (на единицу площади) сила трения $\mathrm{f}_{\mathrm{fr}}=\mathrm{F}_{\mathrm{fr}} / \mathrm{S}=\mu \cdot \mathrm{P}$. Можно убедиться (табл. 2), что удельная сила трения с ростом давления практически не меняется и остаётся величиной, равной $0,5 \div 0,6$ МПа.

Износостойкость композитов в отличие от их прочности повышается с ростом концентрации в них мягкого олова. Наименьшую интенсивность изнашивания при сухом трении по стали демонстрируют образцы с повышенным содержанием олова, и чем выше давление на поверхности трения, тем сильнее выражена эта закономерность. Возможно, что рост нагруз-

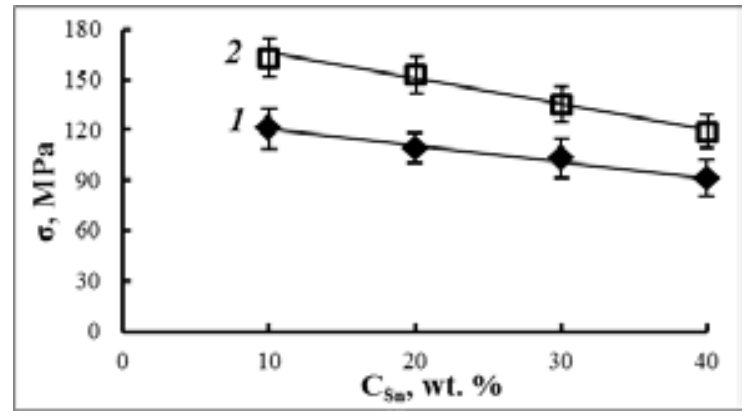

Рис. 3. Зависимость условного предела текучести (1) и предела прочности (2) доуплотненных $\left(250{ }^{\circ} \mathrm{C}\right)$ композитов (Al-12Si)-xSn от концентрации в них олова

Fig. 3. Dependence of the yield strength (1) and ultimate strength (2) of the (Al-12Si)-xSn composites subjected to hot densification on tin content

Таблица 2. Влияние концентрации олова и давления на коэффициент трения ( $\mu$ ) и интенсивность изнашивания (Ih) доуплотненных при $250{ }^{\circ} \mathrm{C}$ композитов (Al-12Si)-xSn

Table 2. Effect of tin content and pressure on the friction coefficient ( $\mu$ ) and wear intensity (Ih) of the (Al-12Si)$\mathrm{xSn}$ composites subjected to hot densification at $250^{\circ} \mathrm{C}$

\begin{tabular}{|c|c|c|c|c|c|c|c|c|c|}
\hline \multirow{2}{*}{ Состав } & \multicolumn{7}{|c|}{ Коэффициент трения, $\boldsymbol{\mu}$} & \multicolumn{1}{|c|}{ Интенсивность изнашивания, мкм/м } \\
\cline { 2 - 9 } & \multicolumn{9}{|c|}{ ДПа } \\
\cline { 2 - 9 } & $\mathbf{1}$ & $\mathbf{3}$ & $\mathbf{4}$ & $\mathbf{5}$ & $\mathbf{1}$ & $\mathbf{3}$ & $\mathbf{4}$ & $\mathbf{5}$ \\
\hline $\mathbf{( A l - 1 2 S i ) - 1 0 S n}$ & 0,62 & 0,20 & 0,14 & 0,11 & 0,11 & 0,19 & 0,26 & 0,34 \\
\hline (Al-12Si)-20Sn & 0,55 & 0,22 & 0,14 & 0,11 & 0,1 & 0,16 & 0,24 & 0,21 \\
\hline (Al-12Si)-30Sn & 0,54 & 0,21 & 0,14 & 0,11 & 0,13 & 0,17 & 0,22 & 0,20 \\
\hline (Al-12Si)-40Sn & 0,61 & 0,20 & 0,14 & 0,11 & 0,10 & 0,14 & 0,21 & 0,18 \\
\hline
\end{tabular}


ки на образец способствует выдавливанию из него на поверхность трения дополнительного количества олова. Это олово перемешивается с материалом матрицы в деформируемом слое и пластифицирует его. Чем больше олова выдавливается, тем при больших испытанных деформациях поверхностный слой начинает разрушаться с образованием частиц износа.

Рост давления на поверхности трения закономерно усиливает интенсивность изнашивания образцов вследствие нарастания проходящего через неё потока механической энергии $\left(\mathrm{P} \cdot \mathrm{V}_{\mathrm{ck}}\right)$. Большая часть этого потока трансформируется в тепло и разогревает поверхность трения. Наконец, может настать такой момент, когда подводимого тепла будет достаточно для расплавления олова в поверхностном слое. Судя по данным табл. 2, такой режим трения наступает при давлении выше 4 МПа и сопровождается заметным снижением интенсивности изнашивания КМ с большим количеством олова. Исключение составляет композит (Al-12Si)-10Sn, поскольку ввиду низкой концентрации плохо проводящего тепло Sn он имеет высокую теплопроводность и меньше разогревается.

В заключение следует отметить ещё один положительный факт большого содержания олова в композитах на основе алюминия. В процессе сухого трения алюминия по стали, как известно, в его поверхностном слое образуется дополнительное количество твёрдых оксидов, которые начинают царапать поверхность стального контртела. Олово пластифицирует поверхностный слой, оксиды закрепляются уже не столь жёстко и меньше выступают над поверхностью образца. Это приводит к снижению повреждаемости ими поверхности контртела. Так, из сравнения на рис. 4 фотографий дорожек трения после испытаний при давлении 5 МПа и прохождения образцом 500 м видно, что дорожка трения после фрикционного контакта с композитом (Al-12Si)$30 \mathrm{Sn}$ действительно более гладкая, чем после аналогичного контакта с КM (Al-12Si)-10Sn.

\section{Выводы}

Из вышеизложенного следует, что все поставленные в работе цели достигнуты.

1. Было показано, что существует режим жидкофазного спекания прессовок из смеси порошков Sn и сплава (Al-12Si), позволяющий получать материалы со связанной матрицей в широком диапазоне содержания олова.

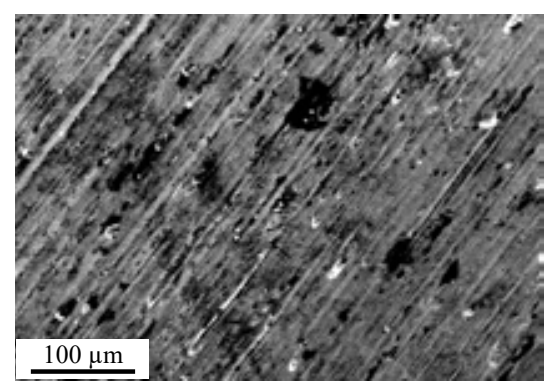

a

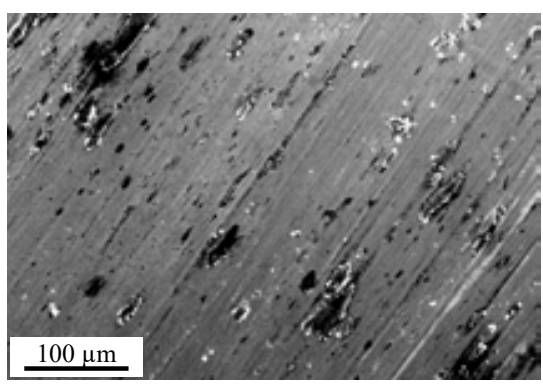

6

Рис. 4. Вид дорожек трения на стальном диске после прохождения 500 м образцами (Al-12Si)-10Sn (a) и (Al-12Si)-30Sn (б). Давление на поверхность трения 5 МПа

Fig. 4. Image of the friction tracks on the steel disk after sliding distance $500 \mathrm{~m}$ of the (Al-12Si)-10Sn (a) and (Al12Si)-30Sn (б) samples. The pressure on the friction surface was $5 \mathrm{MPa}$ 
2. Установлено, что для повышения прочности и пластичности спечённых композитов их необходимо подвергнуть горячей допрессовке желательно при температуре, близкой или даже несколько более высокой, чем точка плавления олова. Прочность горячепрессованных образцов зависит от содержания в них олова и описывается правилом идеальной смеси.

3. Доказано, что с ростом концентрации олова в спечённых композитах (Al-12Si)-xSn интенсивность их изнашивания при сухом трении по стальному контртелу снижается. Особенно заметно этот эффект выражен при повышенном давлении на поверхности трения.

Статья подготовлена по материалам доклада, представленного на IХ международном конгрессе «Цветные металлы и минералы-2017».

Работа выполнена в рамках проекта СО РАН (программа III.23.2.4) при частичном финансировании по проектам РФФИ (№ 16-08-00603 и № 16-38-00236).

\section{Список литературы}

[1] Алиева С.Г., Альтман М.Б., Амбарцумян С.М. и др. Промышленные алюминиевые сплавыl: Справ. изд. М.: Металлургия, 1984. 528 с. [Alieva S.G., Altman M.B., Ambartsumyan S.M., ect. Industrial aluminum alloys: Ref. ed., Moskow, 1984, 528 p. (in Russian)]

[2] Abed E.J. Study of solidification and mechanical properties of Al-Sn casting alloys, Asian Transaction on Engineering, 2012, 2(3), 89-98.

[3] Буше Н.А., Двоскина В.А., Раков К.М., Гуляев А.С. Подшипники из алюминиевых сплавов. М.: Транспорт, 1974. 256 с [Bushe N.A., Dvoskina V.A., Rakov K.M., Gulyaev A.S. Bearings made of aluminum alloys, Moskow, Transport, 1974, 256 p. (in Russian)]

[4] Zhiming W., Haoran G., Zhongquan G., Xinying T. Temperature-induced anomalous structural changes of Al-12wt. \%Sn-4wt. \%Si melt and influence on as-cast structure, China foundry, 2010, 7(2), 138-142.

[5] Goudar D.M., Srivastava V.C., Rudrakshi G.B., Raju K., Ojha S.N. Effect of tin on the wear properties of spray formed Al-17Si alloy, Trans Indian Inst Met, 2015, DOI 10.1007/s12666-0150573-1.

[6] Русин Н.М., Скоренцев А.Л. Способ получения износостойкого антифрикичинного сплава. Патент RU 2552208, 2015 [Rusin N.M., Skorentsev A.L. Method of obtaining a wear-resistant antifriction alloy, Patent $R U$ 2552208, 2015. (in Russian)]

[7] Kingery W.D. Densification during sintering in the presence of a liquid phase, J. Appl. Phys., 1959, 30(3), 301-306.

[8] Русин Н.М., Скоренцев А.Л. Спекание как метод получения прочных композитов Al-Sn с большим содержанием второй фазы. Известия вузов. Порошковая металлургия и функииональные покрытия, 2017, 1, 20-28 [Rusin N.M., Skorentsev A.L. Sintering as a method for obtaining the durable Al-Sn composites with high content of second phase, Proceedings of high schools. Powder Metallurgy and Functional Coatings, 2017, 1, 20-28 (in Russian)]

[9] Straumal B., Molodov D., Gust W. Grain boundary wetting phase transitions in the Al-Sn and Al-Sn-Pb systems, Materials science forum, 1996, 207-209, 437-440.

[10] German R.M. Liquid Phase Sintering, Plenum press, New York, 1985, 249 p.

$$
-442-
$$

